(2) Open Access Full Text Article

\title{
$\mathrm{N}$-acetylcysteine and meso-2,3-
}

\section{dimercaptosuccinic acid alleviate oxidative stress and hepatic dysfunction induced by sodium arsenite in male rats}

\author{
This article was published in the following Dove Press journal: \\ Drug Design, Development and Therapy \\ 20 October 2016 \\ Number of times this article has been viewed
}

\author{
Ahmed M Abu El-Saad ${ }^{1,4}$ \\ Mohammed A Al-Kahtani ${ }^{2}$ \\ Ashraf M Abdel-Moneim ${ }^{3,4}$ \\ 'Department of Biology, Faculty \\ of Medicine, Dammam University, \\ Dammam, Saudi Arabia; ${ }^{2}$ Department \\ of Biology, Faculty of Science, King \\ Khalid University, Abha, Saudi Arabia; \\ ${ }^{3}$ Department of Biological Sciences, \\ Faculty of Science, King Faisal \\ University, Al-Ahsa, Saudi Arabia; \\ ${ }^{4}$ Department of Zoology, Faculty \\ of Science, Alexandria University, \\ Alexandria, Egypt
}

Correspondence: Ashraf M AbdelMoneim

Department of Biological Sciences, Faculty of Science, King Faisal University, Al-Ahsa 31982, Saudi Arabia Tel +966 0I3 5897439 Email aabdelmoneim@kfu.edu.sa
Abstract: Environmental exposure to arsenic represents a serious challenge to humans and other animals. The aim of the present study was to test the protective effect of antioxidant $\mathrm{N}$-acetylcysteine (NAC) either individually or in combination with a chelating agent, meso2,3-dimercaptosuccinic acid (DMSA), against sodium arsenite oral toxicity in male rats. Five groups were used: control; arsenic group (orally administrated in a concentration of $2 \mathrm{mg} / \mathrm{kg}$ body weight [b.w.]); the other three groups were orally administrated sodium arsenite in a concentration of $2 \mathrm{mg} / \mathrm{kg}$ b.w. followed by either NAC $(10 \mathrm{mg} / \mathrm{kg}$ b.w., intraperitoneally [i.p.]), DMSA (50 mg/kg b.w., i.p.) or NAC plus DMSA. Arsenic toxicity caused significant rise in serum aspartate aminotransferase, alanine aminotransferase and total bilirubin, and a significant decrease in total protein (TP) and albumin levels after 3 weeks of experimental period. In addition, arsenic-treated rats showed significantly higher arsenic content in liver and significant rise in hepatic malondialdehyde level. By contrast, sharp decreases in glutathione content and catalase and glutathione reductase activities were discernible. NAC and/or DMSA counteracted most of these physiologic and biochemical defects. NAC monotherapy was more effective than DMSA in increasing TP, while DMSA was more effective in decreasing alanine aminotransferase. The combined treatment was superior over monotherapies in recovery of TP and glutathione. Biochemical data were well supported by histopathological and ultrastructural findings. In conclusion, the combination therapy of NAC and DMSA may be an ideal choice against oxidative insult induced by arsenic poisoning.

Keywords: arsenic, N-acetylcysteine, meso-2,3-dimercaptosuccinic acid, liver pathology, oxidative imbalance

\section{Introduction}

Arsenic contamination of drinking water and human diet poses serious health problems across the world. This element is abundant in some rocks of earth's crust, and the excessive applications of agricultural insecticides and rodenticides increase arsenic contamination in ground water. ${ }^{1,2}$ Exposure to arsenic results in cardiovascular abnormalities, hepatic and renal diseases as well as neurological deficits. ${ }^{3}$ In fact, arsenic has been implicated in the occurrence of various tumors and it is classified as a group I carcinogen. ${ }^{4-6}$ Liver is one of the target organs of arsenic toxicity and carcinogenesis. ${ }^{7,8}$ Epidemiological studies have indicated that chronic arsenic exposure causes abnormal liver function and hepatotoxicity. ${ }^{9}$ Previous studies have revealed that arsenic induces hepatic oxidative injury and overproduction of reactive oxygen species (ROS), which 
could be detrimental to biological membranes. ${ }^{10,11}$ Thus, increasing the cellular antioxidant capacity has become an appropriate approach to abolish arsenic toxicity. ${ }^{12,13}$

$\mathrm{N}$-acetylcysteine (NAC) is an organosulfur antioxidant derived from Allium plants. It is reported to exert a hepatoprotective activity. ${ }^{14}$ NAC has both mucolytic and anticarcinogenic properties. ${ }^{15}$ As a source of sulfhydryl groups, NAC is able to restore endogenous antioxidant potential, promote detoxification and act as a strong scavenger of toxic radicals such as $\mathrm{OH}^{\cdot}$ and $\mathrm{H}_{2} \mathrm{O}_{2} \cdot{ }^{16} \mathrm{NAC}$ was also shown to have antiinflammatory and immunomodulatory effects, leading to increase of liver repair. ${ }^{17}$ It is a standard chemoprotective drug against the toxicity of carcinogenic metals. ${ }^{18,19}$ Additionally, NAC has cytoprotective effect caused by inorganic arsenic. ${ }^{20}$ On the other hand, chelating agents such as meso-2,3-dimercaptosuccinic acid (DMSA) were used as antidotes for acute and chronic metal poisoning in laboratory animals. ${ }^{21}$ DMSA is hydrophilic and belongs to the mercapto family, which has vicinal dithiol moiety for the binding of metals. Clinical trials and research establish this compound as the major metal chelator, based on renal metal excretion and its safety attributes compared to other types of chelating legends. ${ }^{22}$ Interestingly, several authors highlighted the usefulness of combination therapy instead of monotherapy with chelators/ antioxidants against toxic effects of metals. ${ }^{23-28}$ In this regard, Flora $^{29}$ and Kannan and Flora ${ }^{30}$ reported the reduction of tissue oxidative stress by DMSA (or its analogs) and NAC in rats exposed to chronic arsenic via drinking water. In the present study, we demonstrated the pharmaceutical effects of DMSA/ NAC on liver injury induced by short-term (subacute) toxicity of arsenic in male rats. Specifically, biochemical parameters indicative of hepatocellular damage and ROS production were analyzed. Liver histological and ultrastructural anomalies were also monitored at the same time.

\section{Materials and methods Chemicals}

Sodium arsenite $\left(\mathrm{NaAsO}_{2}\right.$, molecular weight 129.9), NAC and DMSA were purchased from Sigma Chemicals, St Louis, MO, USA. All other chemicals and reagent used in this work were of analytical grade. NAC was dissolved and diluted in sterile normal saline ( $\mathrm{pH}$ 7.2). DMSA was freshly prepared in $10 \% \mathrm{NaHCO}_{3}$ solution. The arsenic compound, $\mathrm{NaAsO}_{2}$, was dissolved in distilled water instantly prior to use.

\section{Animals}

Adult male albino rats (10-13 weeks, 150-200 g) were obtained from an animal facility at Alexandria University, Egypt. Animals were housed in plastic cages in a well-ventilated room; they had free access to standard lab chow and water for 1 week before and during the experiment. Rats were also maintained at controlled temperature of $25^{\circ} \mathrm{C}-27^{\circ} \mathrm{C}$ in 12-hour light/12-hour dark photoperiod schedule.

\section{Treatments and tissue collection}

Male albino rats were divided randomly into five groups (eight rats per group); animals were treated for 3 weeks as follows:

1. Group 1: injected (i.p.) with saline (control).

2. Group 2: received $2 \mathrm{mg} \mathrm{NaAsO} / \mathrm{kg}$ b.w. orally once daily.

3. Group 3: received $\mathrm{NaAsO}_{2}$ as described in Group 2 followed by $10 \mathrm{mg} \mathrm{NAC/kg} \mathrm{b.w.} \mathrm{(i.p.)} \mathrm{once} \mathrm{daily.}$

4. Group 4: received $\mathrm{NaAsO}_{2}$ as described in Group 2 followed by $50 \mathrm{mg}$ DMSA/kg b.w. (i.p.) once daily.

5. Group 5: received $\mathrm{NaAsO}_{2}$ followed by NAC and DMSA (as described in Groups 2, 3 and 4).

Doses of arsenic, NAC, and DMSA were selected based on previous studies. ${ }^{27,31}$ Animals were fasted overnight after the end of treatment, and then they were sacrificed under diethyl ether anesthesia. Blood was taken from abdominal aorta, then serum was separated via centrifugation and stored at $-20^{\circ} \mathrm{C}$ until assay. Half portion of liver was removed, rinsed in cold saline $(0.9 \% \mathrm{NaCl})$, blotted, weighted and processed immediately for biochemical estimation, and a small part of tissue was stored at $-20^{\circ} \mathrm{C}$ for wet acid digestion and analysis of arsenic content. The remaining intact liver tissues were taken for light and electron microscopy. The experimental design was in accordance with the National Institute of Health (NIH) guidelines for the care and use of laboratory animals and the treatment protocols were approved by a local committee review at Alexandria University.

\section{Biochemical analyses \\ Liver function tests}

Aspartate aminotransferase (AST), alanine aminotransferase (ALT), and total bilirubin (TB) were assayed in serum according to the standard spectrophotometric procedures described by the manufacturers (Sigma Diagnostics (I) Pvt. Ltd., Baroda, India). Serum albumin was estimated using a specific kit (Thermo Trace-BECGMAN, Germany). Total protein (TP) content was determined by the method of Lowry et $\mathrm{al}^{32}$ using bovine serum as standard.

\section{Assay for redox status in tissue homogenates}

An amount of $200 \mathrm{mg}$ of liver sample was taken and homogenized in $50 \mathrm{mM}$ potassium phosphate buffer containing $1 \mathrm{mM}$ ethylenediaminetetraacetic acid (EDTA) ( $\mathrm{pH} 7.4)$. 
The homogenate $(10 \%)$ was centrifuged at $10,000 \times g$ for 20 minutes at $4{ }^{\circ} \mathrm{C}$; the resultant supernatant was used for oxidative stress-related parameters. Lipid peroxidation (LPO) was determined by thiobarbituric acid method, which estimates the malondialdehyde (MDA) formation..$^{33}$ Levels of reduced glutathione (GSH) were detected by the method of Ellman. ${ }^{34}$ The activity of glutathione reductase (GR) was measured by monitoring the oxidation of nicotinamide adenine dinucleotide phosphate (NADPH) at $340 \mathrm{~nm}$ in the presence of oxidized GSH according to Beutler. ${ }^{35}$ Catalase (CAT) activity was evaluated as previously described by the method of Sinha. ${ }^{36}$

\section{Estimation of arsenic residues in liver}

Liver samples were wet acid digested ${ }^{37}$ and the concentration of arsenic in the digested samples were measured according to Nandi et $\mathrm{al}^{38}$ using atomic absorption spectrophotometer (ECIL-4141; ECIL, Hyderabad, India) at 193.7 nm wavelength and $10 \mathrm{~mA}$ current. Samples were analyzed against standards within the linear range of the calibration. The values were expressed in microgram per gram of tissue. The detection limit for arsenic was $0.02 \mathrm{ppm}$. Analytical accuracy was ensured by repeated analysis of test samples; eight freshly prepared standards and reagent blanks were run with each analytical series.

\section{Histological study}

Livers were fixed in 10\% neutral buffered formalin. From each tissue sample, $4 \mu \mathrm{m}$ sections were prepared and stained with routine hematoxylin-eosin. The micrographs of the relevant stained sections were subsequently taken with the aid of Olympus light microscope.

\section{Electron microscopic examination}

Small pieces of liver $(1-3 \mathrm{~mm})$ were fixed in $2.5 \%$ glutaraldehyde (buffered) for 3 hours at $4^{\circ} \mathrm{C}$. Subsequently, samples were postfixed in 1\% osmium tetroxide (cold) in $0.1 \mathrm{M}$ phosphate or cacodylate buffer ( $\mathrm{pH}$ 7.2) for 1 hour. Samples were then flushed in phosphate buffer, dehydrated in increasing series of ethanol and embedded in Araldite. Ultrathin sections $(80-100 \mathrm{~nm})$ were obtained with an ultramicrotome (Nova; LKB Inc., Bromma, Sweden). Sections were mounted on 200 mesh $\mathrm{Cu}$ grids, double stained with $4 \%$ uranyl acetate (15 minutes) followed by $1 \%$ lead citrate ( 2 minutes) and materials were viewed under a Jeol-CX-100 transmission electron microscope at $80 \mathrm{kV}$.

\section{Statistics}

Experimental data were analyzed using analysis of variance followed by post hoc comparisons for mean values. Results were presented as mean \pm standard error of mean, and $P$-values less than 0.05 were considered significant.

\section{Results \\ Biochemical findings}

Oral administration of arsenic caused a significant increase in the activities of serum AST (+61.8\%), ALT (+203.4\%), and bilirubin level $(+108.7 \%)$, but statistically significant reduction was found in TP concentration $(-42 \%)$ and albumin level $(-18.5 \%)$ when compared with control group (Figure 1A-E). Monotherapy with NAC and the combined treatment of NAC + DMSA resulted in a significant decrease in serum AST activity compared to the arsenic group; AST was restored to normal values only after combined treatment (Figure 1A). Meanwhile, NAC-alone did not significantly reduce serum ALT activity, which responded significantly to both DMSA-alone and NAC + DMSA. However, only NAC + DMSA combined treatment revealed a maximum reduction in the enzyme activity without attaining control values (Figure 1B). However, treatment with NAC, DMSA and their combination after arsenic exposure significantly reduced the increased serum bilirubin level compared to the arsenic-treated group. Three weeks of cotreatment with NAC + DMSA provoked a more intensive lowering in arsenic-induced elevation of serum bilirubin level compared to individual treatments and restored its level near to the control (Figure 1C). The inhibited level of serum TP after treatment with arsenic was significantly elevated in rats treated with NAC, DMSA, and NAC + DMSA compared to arsenic-intoxicated group. Remarkably, the combination treatment with NAC + DMSA produced a recovery in serum protein level over that by either of them alone, although it was still significantly lower than those of healthy controls (Figure 1D). Anywise, NAC or DMSA monotherapy and the combined treatment of NAC + DMSA failed to protect against arsenic-induced reduction of serum albumin (Figure 1E).

Compared to the control group, LPO level was markedly increased in the arsenic-exposed rats as exhibited by a significant increase in the level of hepatic MDA (+46.2\%). In addition, the level of GSH (-40\%) and activities of GR $(-47.6 \%)$ and CAT $(-39.6 \%)$ were significantly decreased (Figure 2A-D). DMSA-alone treatment or in combination with NAC showed a more pronounced reduction and retrieved MDA level toward normalization, while treatment with NAC-alone was unable to reduce the increase in the hepatic MDA level (Figure 2A). The level of GSH and the activity of GR were significantly elevated after treatment with NAC, DMSA, and NAC + DMSA compared 


\section{A}

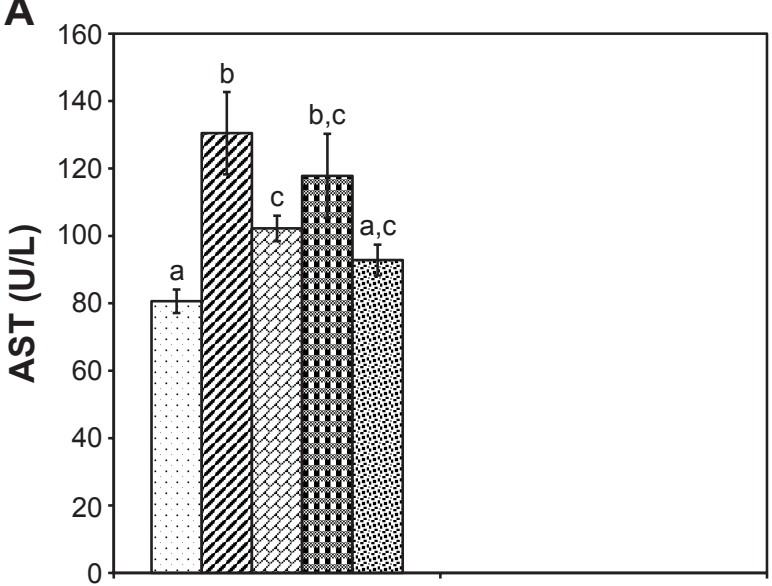

C

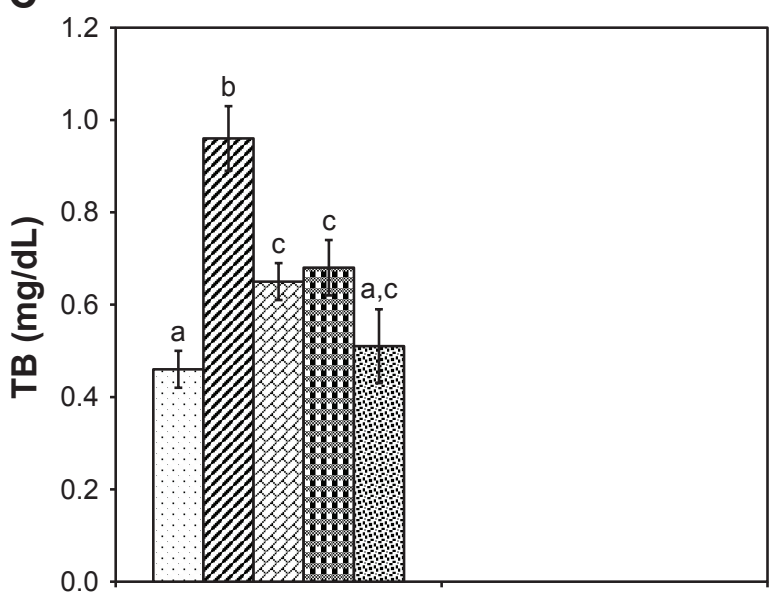

B

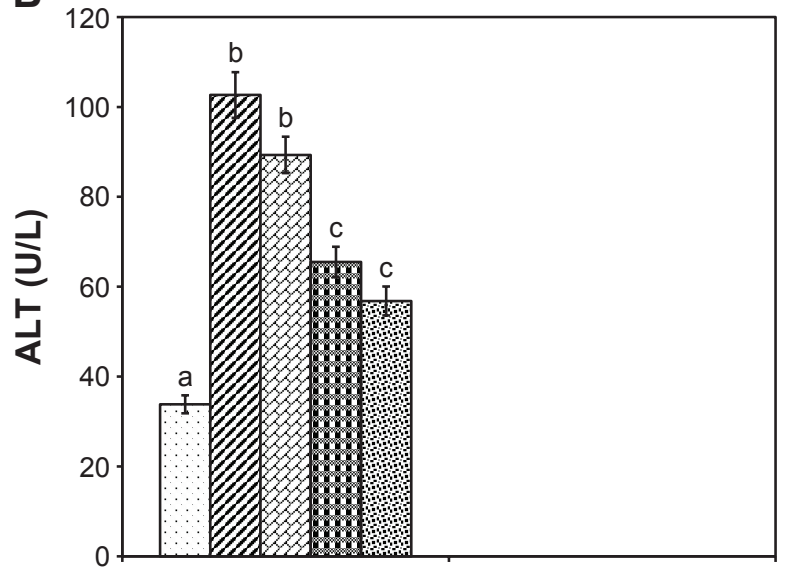

D

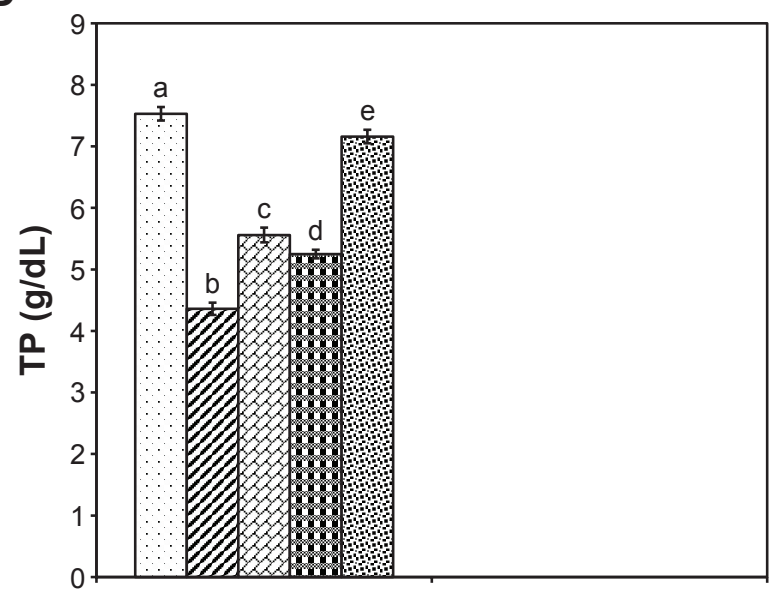

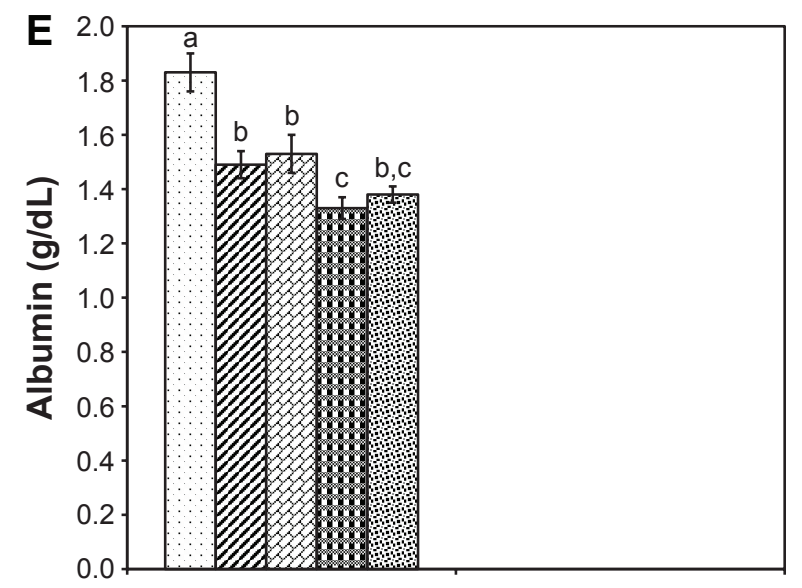

$\square$ Control $\square$ AS $\square$ AS + NAC AS + DMSA

Figure I Effect of NAC and/or DMSA on arsenic induced changes in serum levels of AST (A), ALT (B), TB (C), TP (D), and albumin (E). Each bar represents mean \pm SE of eight animals in each group. Bar superscripts with no common letters $(a-e)$ are significantly different $(P<0.05)$.

Abbreviations: NAC, N-acetylcysteine; DMSA, meso-2,3-dimercaptosuccinic acid; AST, aspartate aminotransferase; ALT, alanine aminotransferase; TB, total bilirubin; TP, total protein; SE, standard error; AS, arsenic.

to the arsenic-treated group. Strikingly, only the combination of NAC + DMSA efficiently restored the inhibited GSH level to near normal (Figure 2B), whereas treatment with NAC and/or DMSA enhanced GR activity toward normalization (Figure 2C). After arsenic administration, the activity of CAT in rats given separate treatments of NAC or DMSA was the same as those treated with arsenic alone. Notably, only the combination of NAC + DMSA efficiently restored the inhibited CAT activity to near normal (Figure 2D). 
A

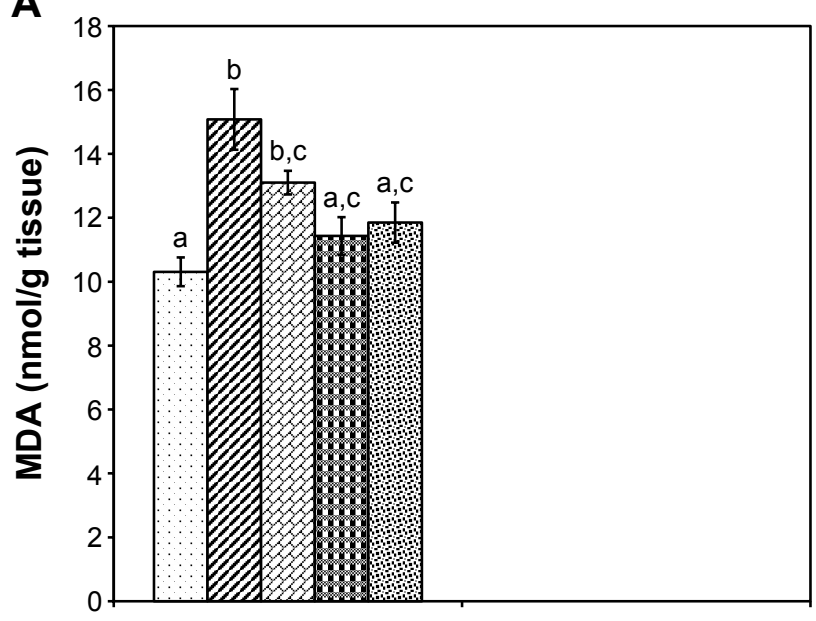

C

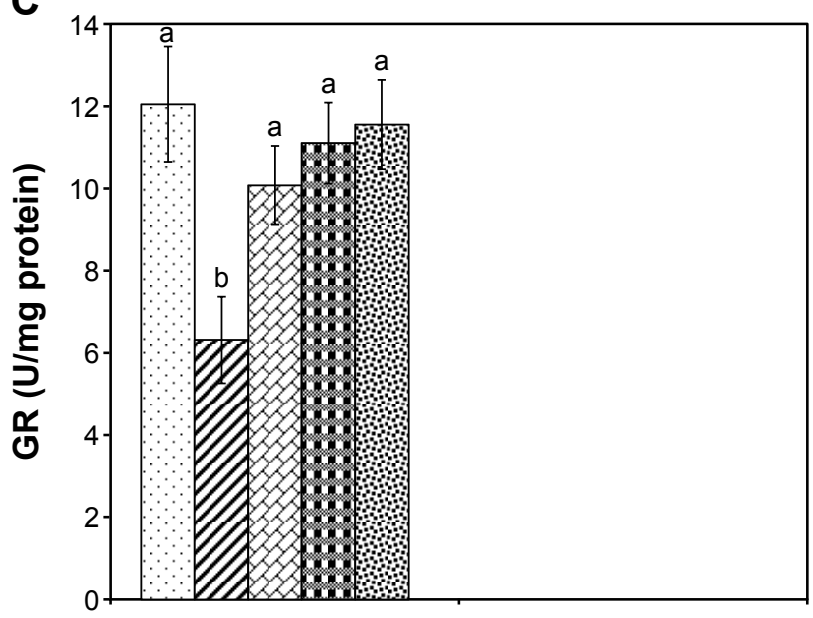

B

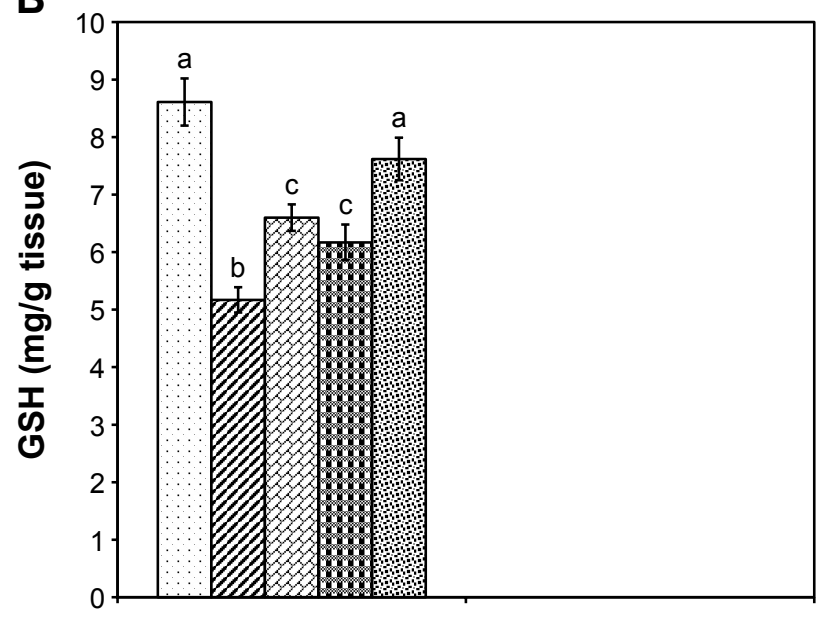

D

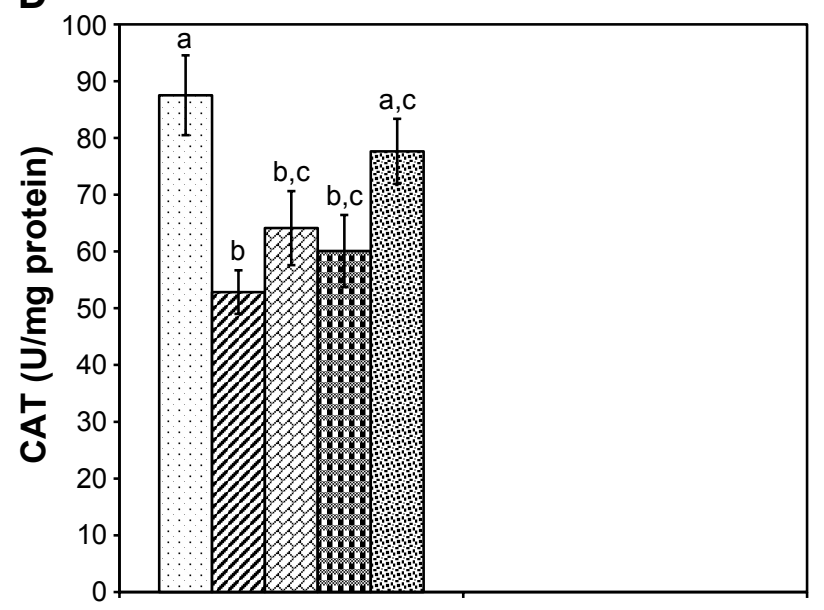

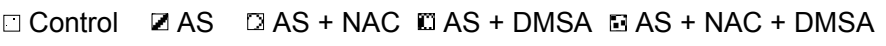

Figure 2 Effect of NAC and/or DMSA on arsenic induced changes in hepatic MDA (A), GSH (B), GR (C), and CAT (D). Each bar represents mean \pm SE of eight animals in each group. Bar superscripts with no common letters $(a-c)$ are significantly different $(P<0.05)$.

Abbreviations: NAC, N-acetylcysteine; DMSA, meso-2,3-dimercaptosuccinic acid; MDA, malondialdehyde; GSH, glutathione; GR, glutathione reductase; CAT, catalase; SE, standard error; AS, arsenic.

\section{Changes of arsenic accumulation}

In arsenic group, there was a significant increase in arsenic accumulation in hepatic tissue $(+1,350 \%)$ compared to controls (Figure 3). A notable reduction of arsenic levels in liver tissue was recorded in arsenic-exposed rats given NACalone $(-50.2 \%)$ and DMSA-alone $(-61.6 \%)$ as compared to the arsenic group. However, a better recovery in arsenic accumulation was observed in hepatic tissue in rats treated with combined NAC + DMSA (-68.2\%) as compared to the arsenic-intoxicated group. The level of arsenic remained significantly higher than the control in all exposed groups.

\section{Histopathological observations}

As shown in Figure 4A, the livers of control rats showed normal histology. The hepatic tissue from arsenic-treated rats displayed focal hepatocyte degeneration, hemorrhagic lesions,

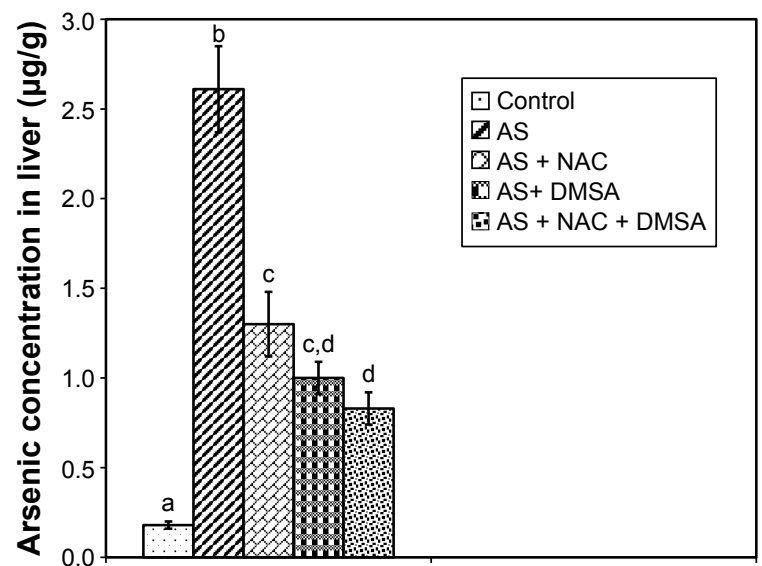

Figure 3 Effect of NAC and/or DMSA on the concentration of arsenic in liver. Each bar represents mean \pm SE of eight animals in each group. Bar superscripts with no common letters $(a-d)$ are significantly different $(P<0.05)$.

Abbreviations: NAC, N-acetylcysteine; DMSA, meso-2,3-dimercaptosuccinic acid; SE, standard error; AS, arsenic. 
and massive inflammatory cell infiltration (Figure 4B). The damage was clearly less severe after treatment with NAC (Figure 4C) and DMSA (Figure 4D), but discrete changes were still observed. The liver architecture was normal in most areas after combined NAC/DMSA treatment regimen with no evidence of leukocyte infiltrates (Figure 4E).

\section{Liver ultrastructural changes}

Liver of control rats had normal cytoarchitecture (Figure 5A). Fine structure of liver of the arsenic-treated group revealed dramatic modifications in cell structure, including cytoplasmic vacuolization, diminished rough endoplasmic reticulum (RER) cisternae, few number of disrupted mitochondria, and condensation of nuclear chromatin (ie, pyknosis) (Figure 5B). Decreased degenerative areas and vacuolization, increased RER membranes in hepatocytes, and rarely pyknotic nuclei were seen after NAC treatment (Figure 5C). Also, DMSA treatment after arsenic showed an ameliorative appearance of RER, mitochondria, and nucleus (Figure 5D). Hepatocytes regained
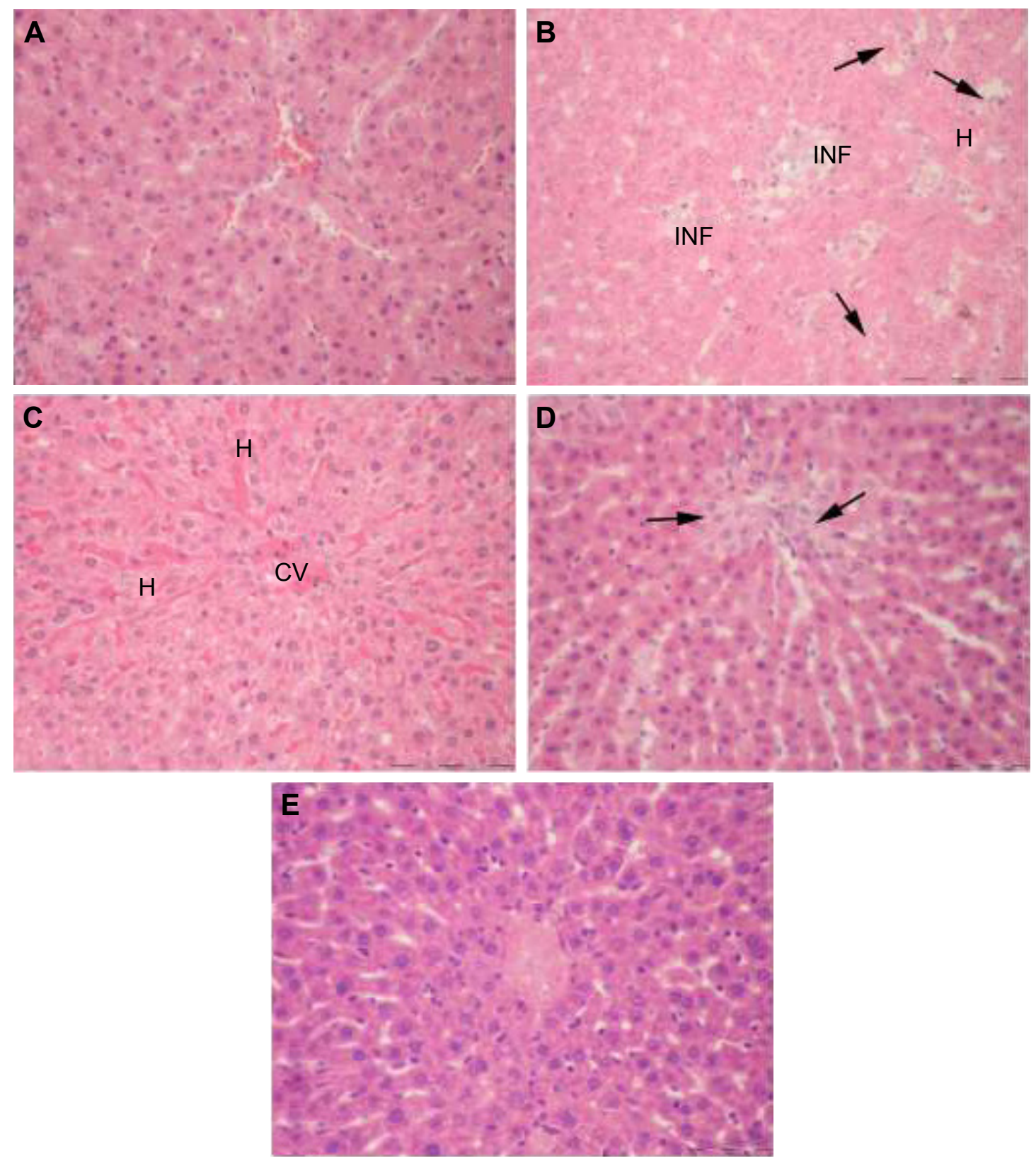

Figure 4 Microphotographs of $\mathrm{H}$ and E-stained liver sections of rats. (A) Control depicts normal liver parenchyma. (B) Arsenic: note degeneration of hepatocytes (arrows), vascular congestion/hemorrhage (H), and multiple inflammatory sites (INF). (C) Arsenic + NAC: hepatocytes are intact but congestion and widening of sinusoidal spaces are still found. (D) Arsenic + DMSA: foci of parenchymal degeneration and necrosis are obvious (arrows). (E) Arsenic + NAC + DMSA: liver architecture is comparable to control without inflammatory characteristics. Original magnification $400 \times(\mathbf{A}-\mathbf{E})$.

Abbreviations: $\mathrm{H}$, hematoxylin; $\mathrm{E}$, eosin; NAC, N-acetylcysteine; CV, central vein; DMSA, meso-2,3-dimercaptosuccinic acid. 

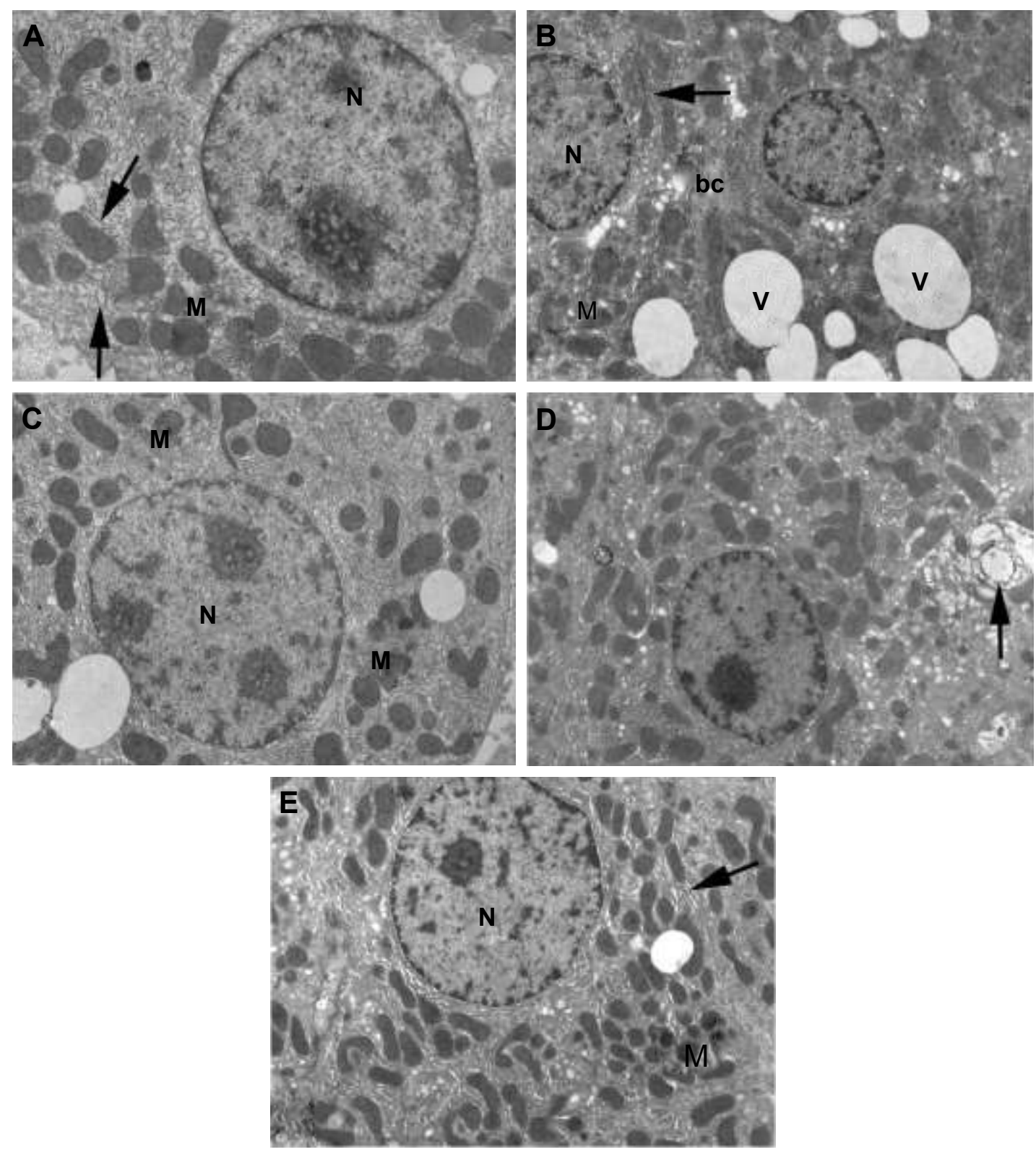

Figure 5 Electron micrographs of liver sections of rats. (A) Control shows hepatocyte with normal cellular organelles and intact nuclear chromatin; $\mathrm{N}$ indicates nucleus, $M$ indicates mitochondria, and arrows indicate endoplasmic reticulum. (B) Arsenic observe increased peripheral chromatin in the nucleus $(N)$, mitochondria (M) with illdefined cristae, few endoplasmic reticulum (arrow) and numerous obvious vacuoles all over the cytoplasm (V); bc indicates bile canaliculus. (C) Arsenic + NAC: note that less condensed chromatin in the nucleus $(\mathrm{N})$, scattered mitochondria $(\mathrm{M})$, and in-between short strands of endoplasmic reticulum are visible. (D) Arsenic + DMSA: the cytoplasm is heavily populated with mitochondria and less fragmented endoplasmic reticulum (compared to B). Notable increase in organelle degeneration is still evident (arrow). (E) Arsenic + NAC + DMSA: hepatocyte is preserved without vacuolization, nucleus (N) without abnormal chromatin, normal mitochondria (M) with intact cristae, normally shaped rough endoplasmic reticulum (arrow). Original magnification 7,500× (A) and 5,000× (B-E).

Abbreviations: NAC, N-acetylcysteine; DMSA, meso-2,3-dimercaptosuccinic acid.

their normal appearance after combined treatment of NAC + DMSA (Figure 5E).

\section{Discussion}

The present study aimed at comparing the effectiveness of NAC and DMSA on subacute hepatotoxicity of arsenic in rats. Exposure to arsenic increased serum levels of AST, ALT, TB, and TP, and decreased albumin level, reflecting a broad hepatocellular damage. These results are in good accordance with those in previous studies. ${ }^{39-43}$ Administration of NAC counteracted arsenic-induced hepatotoxicity as shown by decreased levels of AST and TB, and elevated TP content. In support to the latter results, NAC was reported to have a tendency to avert liver damage via membrane stabilization, thereby suppressing the leakage of hepatic enzymes through membranes..$^{30}$ Also in this work, DMSA monotherapy was 
even better than NAC in relieving ALT, probably due to relatively efficient elimination of arsenic via chelation (Figure 3). Of special interest is the observation that the combined therapy was more beneficial than individual treatments in reversing TP.

There is a growing evidence indicating that arsenic toxicity involves oxidative damage that plays an imperative role in biochemical alterations. Various studies have reported that arsenic exposure generates ROS-like superoxide anion $\left(\mathrm{O}_{2}{ }^{-}\right)$, hydroxyl radical $\left({ }^{\circ} \mathrm{OH}\right)$, hydrogen peroxide $\left(\mathrm{H}_{2} \mathrm{O}_{2}\right)$, singlet oxygen $\left({ }^{1} \mathrm{O}_{2}\right)$, and peroxyl radicals. ${ }^{44}$ A primarily measure of arsenic-induced oxidative stress is the increase in MDA level (a marker of LPO), which is a hallmark of the excess generation of intracellular ROS and hepatotoxicity. ${ }^{29}$ In the present study, arsenic-treated animals showed significantly increased levels of free radical-mediated LPO and decreased levels of GSH, CAT, and GR compared to control. These changes agreed by other researchers such as Flora et al, ${ }^{24,25}$ Messarah et al, ${ }^{41}$ El-Demerdash et al, ${ }^{45}$ Jain et al, ${ }^{46}$ Manimaran et al, ${ }^{47}$ Kotyzová et al, ${ }^{48}$ and Mohanta et al. ${ }^{49}$ The increase in $\mathrm{O}_{2}{ }^{-}$by arsenic decreases CAT activity. ${ }^{50,51}$ The decreased CAT activity may relate to their effective functioning for elimination of hepatic ROS. Moreover, the inhibition of GR leads to accumulation of the pro-oxidant glutathione disulfide by preventing reduction of GSSG to GSH, suggesting that GR may not compensate the consumption of GSH. Some of the ultrastructural changes observed in arsenic-treated rats including fragmentation of RER, breakdown of mitochondrial cristae and disturbed nuclear chromatin are typical for increased ROS and impairment of protein synthesis. By contrast, the ultrastructural picture of liver following antioxidant and/or chelator therapies revealed a healthy appearance. The improvement was more obvious with NAC + DMSA, which assisted to an overall enhancement of the antioxidant defense system. In full broad agreement with these structural observations, the biochemical data showed that the combined NAC + DMSA treatment after arsenic yielded more GSH levels compared with NAC and DMSA alone. NAC interacts most strongly with ${ }^{\circ} \mathrm{OH}$ radicals $;{ }^{52}$ it exerts an indirect effect on antioxidant status, since it restores CAT and is a precursor for synthesis of GSH, thus providing enhanced protection against toxininduced oxidative insult. ${ }^{53}$ DMSA has also an important role in decreasing the oxidative stress, either by eliminating the toxic metal from the target organ and/or by directly scavenging ROS via its sulfhydryl groups. ${ }^{25}$ DMSA chelator effectively interacts with arsenic in the cell, forming a saturated five-member heterocyclic ring namely 1,3-dithiol-2-arsolan. Following this, mobilization of arsenic is increased via the kidneys, which might be one of the reasons for the increase in the activities of enzymatic antioxidants. ${ }^{54}$

Polyunsaturated fatty acids in cell membrane are very susceptible to free radical attack, which initiates the self-propagating LPO reactions ${ }^{55}$ resulting in the loss of membrane fluidity, decreased membrane potential, increased permeability of protons and $\mathrm{Ca}^{2+}$, and inactivation of a several membrane-bound enzymes. ${ }^{56}$ Thus, arsenic-induced LPO leads to the degradation of phospholipids and finally prompts cellular deterioration in liver. In this research, DMSA or $\mathrm{NAC}+\mathrm{DMSA}$ therapeutic regimens achieved the best effect and were able to normalize LPO levels.

\section{Conclusion}

The present study confirmed the valuable effect of NAC and DMSA chelator against oxidant/antioxidant imbalance induced by short-term arsenic. The action of NAC against arsenic burden may be complementary to that of DMSA, but the underlying molecular mechanisms need further investigations.

\section{Disclosure}

The authors report no conflicts of interest in this work.

\section{References}

1. Jiang J-Q, Ashekuzzaman SM, Jiang A, et al. Arsenic contaminated groundwater and its treatment options in Bangladesh. Int JEnviron Res Public Health. 2013;10(1):18-46.

2. Dwivedi N, Flora G, Kushwaha P, Flora SJ. Alpha-lipoic acid protects oxidative stress, changes in cholinergic system and tissue histopathology during co-exposure to arsenic-dichlorvos in rats. Environ Toxicol Pharmacol. 2014;37(1):7-23.

3. Anetor JI, Wanibuchi H, Fukushima S. Arsenic exposure and its health effects and risk of cancer in developing countries: micronutrients as host defence. Asian Pac J Cancer Prevention. 2007;8:13-23.

4. Flora SJS, Pachauri V. Chelation in metal intoxication. Int J Environ Res Public Health. 2010;7(7):2745-2788.

5. Naujokas MF, Anderson B, Ahsan H, et al. The broad scope of health effects from chronic arsenic exposure: update on a worldwide public health problem. Environ Health Perspect. 2013;121(3):295-302.

6. IARC. International agency for research on cancer IARC monographs on the evaluation of carcinogenic risks to humans. IARC Monogr Eval Carcinog Risks Hum. 2002;96:1-390.

7. Patra PH, Bandyopadhyay S, Kumar R, et al. Quantitative imaging of arsenic and its species in goat following long term oral exposure. Food Chem Toxicol. 2012;50(6):1946-1950.

8. Dixit G, Singh AP, Kumar A, et al. Sulfur mediated reduction of arsenic toxicity involves efficient thiol metabolism and the antioxidant defense system in rice. J Hazard Mater. 2015;298:241-251.

9. Guha Mazumder DN. Chronic arsenic toxicity \& human health. Indian J Med Res. 2008;128(4):436-447.

10. Santra A, Maiti A, Chowdhury A, Mazumder DN. Oxidative stress in liver of mice exposed to arsenic-contaminated water. Indian J Gastroenterol. 2000;19(3):112-115.

11. Ghatak S, Biswas A, Dhali GK, Chowdhury A, Boyer JL, Santra A. Oxidative stress and hepatic stellate cell activation are key events in arsenic induced liver fibrosis in mice. Toxicol Appl Pharmacol. 2011;251(1):59-69. 
12. Das K, Bag S, Sahu R, et al. Protective effect of Corchorus olitorius leaves on sodium arsenite-induced toxicity in experimental rats. Food Chem Toxicol. 2010;48(1):326-335.

13. Rana T, Bera AK, Das S, et al. Effect of ascorbic acid on blood oxidative stress in experimental chronic arsenicosis in rodents. Food Chem Toxicol. 2010;48(4):1072-1077.

14. Nissar AU, Farrukh MR, Kaiser PJ, et al. Effect of N-acetyl cysteine (NAC), an organosulfur compound from Allium plants, on experimentally induced hepatic prefibrogenic events in Wistar rat. Phytomedicine. 2013;20(10):828-833.

15. Flora SJS. Arsenic-induced oxidative stress and its reversibility. Free Radic Biol Med. 2011;51(2):257-281.

16. Baumgardner JN, Shankar K, Hennings L, Albano E, Badger TM, Ronis MJJ. $\mathrm{N}$-acetylcysteine attenuates progression of liver pathology in a rat model of nonalcoholic steatohepatitis. J Nutr. 2008;138(10):1872-1879.

17. Lasram MM, Lamine AJ, Dhouib IB, et al. Antioxidant and anti-inflammatory effects of $\mathrm{N}$-acetylcysteine against malathion-induced liver damages and immunotoxicity in rats. Life Sci. 2014;107(1-2) 50-58.

18. Smith SS, Reyes JR, Arbon KS, Harvey WA, Hunt LM, Heggland SJ. Cadmium-induced decrease in RUNX2 mRNA expression and recovery by the antioxidant $\mathrm{N}$-acetylcysteine (NAC) in the human osteoblast-like cell line, Saos-2. Toxicol In Vitro. 2009;23(1):60-66.

19. Luczak MW, Zhitkovich A. Role of direct reactivity with metals in chemoprotection by $\mathrm{N}$-acetylcysteine against chromium(VI), cadmium(II), and cobalt(II). Free Radic Biol Med. 2013;65:262-269.

20. Chen G, Wang K, Yang BY, et al. Synergistic antitumor activity of oridonin and arsenic trioxide on hepatocellular carcinoma cells. Int $J$ Oncol. 2012;40(1):139-147.

21. El-Sayed MF, Abdel-Ghafar SK, Adly MA, Salim AA, AbdelSamei WM. The ameliorative effects of DMSA and some vitamins against toxicity induced by lead in the testes of albino rats. II. $J$ Basic Appl Zool. 2015;71:60-65.

22. Miller AL. Dimercaptosuccinic acid (DMSA), a non-toxic, watersoluble treatment for heavy metal toxicity. Altern Med Rev. 1998;3(3): 199-207.

23. Flora SJS, Pande M, Mehta A. Beneficial effect of combined administration of some naturally occurring antioxidants (vitamins) and thiol chelators in the treatment of chronic lead intoxication. Chem Biol Interact. 2003;145(3):267-280.

24. Flora SJS, Bhadauria S, Dhaked RK, Pant SC. Arsenic induced blood and brain oxidative stress and its response to some thiol chelators in rats. Life Sci. 2005;77(18):2324-2337.

25. Flora SJS, Chouhan S, Kannan GM, Mittal M, Swarnkar H. Combined administration of taurine and monoisoamyl DMSA protects arsenic induced oxidative injury in rats. Oxid Med Cell Longev. 2008;1(1):39-45.

26. Kokilavani V, Devi MA, Sivarajan K, Panneerselvam C. Combined efficacies of DL- $\alpha$-lipoic acid and meso 2,3 dimercaptosuccinic acid against arsenic induced toxicity in antioxidant systems of rats. Toxicol Lett. 2005;160(1):1-7.

27. Modi M, Kaul RK, Kannan GM, Flora SJ. Co-administration of zinc and n-acetylcysteine prevents arsenic-induced tissue oxidative stress in male rats. J Trace Elem Med Biol. 2006;20(3):197-204.

28. Gupta R, Dubey DK, Kannan GM, Flora SJ. Concomitant administration of Moringa oleifera seed powder in the remediation of arsenic-induced oxidative stress in mouse. Cell Biol Int. 2007;31(1):44-56.

29. Flora SJS. Arsenic-induced oxidative stress and its reversibility following combined administration of $\mathrm{N}$-acetylcysteine and meso 2, 3-dimercaptosuccinic acid in rats. Clin Exp Pharmacol Physiol. 1999; 26(11):865-869.

30. Kannan GM, Flora SJS. Combined administration of N-acetylcysteine and monoisoamyl DMSA on tissue oxidative stress during arsenic chelation therapy. Biol Trace Elem Res. 2006;110(1):43-59.

31. Kalia K, Narula GD, Kannan GM, Flora SJS. Effects of combined administration of captopril and DMSA on arsenite induced oxidative stress and blood and tissue arsenic concentration in rats. Comp Biochem Physiol Pharmacol Toxicol. 2007;144(4):372-379.
32. Lowry OH, Rosebrough NJ, Farr AL, Randall RJ. Protein measurement with the Folin phenol reagent. J Biol Chem. 1951;193(1):265-275.

33. Nair V, Turner GE. The thiobarbituric acid test for lipid peroxidation structure of the adduct with malondialdehyde. Lipids. 1984;19(10):84-95.

34. Ellman GL. Tissue sulfhydryl groups. Arch Biochem Biophys. 1959;82(1): 70-77.

35. Beutler E. Effect of flavin compounds on glutathione reductase activity: in vivo and in vitro studies. J Clin Invest. 1969;48(10):1957-1966.

36. Sinha AK. Colorimetric assay of catalase. Anal Biochem. 1972; 47(2):389-394.

37. Hershey JW, Oostdyk TS, Keliher PN. Determination of arsenic and selenium in environmental and agricultural samples by hydride generation atomic absorption spectrometry. J Assoc Off Anal Chem. 1988;71(6):1090-1093.

38. Nandi D, Patra RC, Swarup D. Effect of cysteine, methionine, ascorbic acid and thiamine on arsenic-induced oxidative stress and biochemical alterations in rats. Toxicology. 2005;211(1-2):26-35.

39. Yousef MI, El-Demerdash FM, Radwan FM. Sodium arsenite induced biochemical perturbations in rats: ameliorating effect of curcumin. Food Chem Toxicol. 2008;46(11):3506-3511.

40. Chattopadhyay S, Maiti S, Maji G, Deb B, Pan B, Ghosh D. Protective role of Moringa oleifera (Sajina) seed on arsenic-induced hepatocellular degeneration in female albino rats. Biol Trace Elem Res. 2011; 142(2):200-212.

41. Messarah M, Klibet F, Boumendjel A, et al. Hepatoprotective role and antioxidant capacity of selenium on arsenic-induced liver injury in rats. Exp Toxicol Pathol. 2012;64(3):167-174.

42. Joshi D, Mittal DK, Shukla S, Srivastav AK, Srivastav SK. N-acetyl cysteine and selenium protects mercuric chloride-induced oxidative stress and antioxidant defense system in liver and kidney of rats: A histopathological approach. J Trace Elem Med. Biol. 2014;28(2):218-226.

43. Muthumani M, Miltonprabu S. Ameliorative efficacy of tetrahydrocurcumin against arsenic induced oxidative damage, dyslipidemia and hepatic mitochondrial toxicity in rats. Chem Biol Interact. 2015 235:95-105.

44. Flora SJS. Arsenic and dichlorvos: possible interaction between two environmental contaminants. J Trace Elem Med Biol. 2016;35:43-60.

45. El-Demerdash FM, Yousef MI, Radwan FME. Ameliorating effect of curcumin on sodium arsenite-induced oxidative damage and lipid peroxidation in different rat organs. Food Chem Toxicol. 2009; 47(1):249-254.

46. Jain A, Yadav A, Bozhkov AI, Padalko VI, Flora SJ. Therapeutic efficacy of silymarin and naringenin in reducing arsenic-induced hepatic damage in young rats. Ecotoxicol Environ Saf. 2011;74(4):607-614.

47. Manimaran A, Sarkar SN, Sankar P. Influence of repeated preexposure to arsenic on acetaminophen-induced oxidative stress in liver of male rats. Food Chem Toxicol. 2010;48(2):605-610.

48. Kotyzová D, Bludovská M, Eybl V. Differential influences of various arsenic compounds on antioxidant defense system in liver and kidney of rats. Environ Toxicol Pharmacol. 2013;36(3):1015-1021.

49. Mohanta RK, Garg AK, Dass RS. Effect of vitamin E supplementation on arsenic induced alteration in blood biochemical profile, oxidant/ antioxidant status, serum cortisol level and retention of arsenic and selenium in goats. J Trace Elem Med Biol. 2015;29:188-194.

50. Kono Y, Fridovich I. Superoxide radical inhibits catalase. J Biol Chem. 1982;257(10):5751-5754.

51. Kirkman HN, Gaetani GF. Catalase: a tetrameric enzyme with four tightly bound molecules of NADPH. Proc Natl Acad Sci US A. 1984; 81:4343-4347.

52. Arakawa M, Ito $\mathrm{Y}$. N-acetylcysteine and neurodegenerative diseases: basic and clinical pharmacology. Cerebellum. 2007;6(4):308-314.

53. Abu El-Saad AM, Elgerbed MS. Dimethoate induced hepatotoxicity in rats and the protective roles of vitamin $\mathrm{E}$ and $\mathrm{N}$-acetylcysteine. Egypt J Exp Biol. 2010;6(2):219-230.

54. Palaniappan PR, Vijayasundaram V. The effect of arsenic exposure and the efficacy of DMSA on the proteins and lipids of the gill tissues of Labeo rohita. Food Chem Toxicol. 2009;47(8):1752-1759. 
55. Pepicelli O, Fedele E, Berardi M, Minghetti L. Cyclo-oxygenase-1 and -2 differently contribute to prostaglandin E 2 synthesis and lipid peroxidation after in vivo activation of $\mathrm{N}$-methyl-D-aspartate receptors in rat hippocampus. J Neurochem. 2005;93(6):1561-1567.
56. Halliwell B, Gutteridge JMC. Free Radicals in Biology and Medicine. 3rd edition. Oxford, UK: Clarendon Press; 1999.

\section{Publish your work in this journal}

Drug Design, Development and Therapy is an international, peerreviewed open-access journal that spans the spectrum of drug design and development through to clinical applications. Clinical outcomes, patient safety, and programs for the development and effective, safe, and sustained use of medicines are the features of the journal, which has also been accepted for indexing on PubMed Central. The manuscript management system is completely online and includes a very quick and fair peer-review system, which is all easy to use. Visit http://www.dovepress.com/testimonials.php to read real quotes from published authors.

Submit your manuscript here: http://www.dovepress.com/drug-design-development-and-therapy-journal 